с позиции главы семьи. Начало совместного бизнеса и вовсе зачастую приводит к краху и брака, и бизнеса. Возникает главная проблема - кто в доме главный, кто больше пользы принес делу.

В Америке, например, семейные фирмы весьма стабильны за счет четкого разделения ролей и явно выраженных партнерских уважительных отношений как в бизнесе, так и в семье. Супруги четко разграничивают рамки своей персональной ответственности, на начальном этапе делят сферы своего влияния. Поэтому, начиная совместный бизнес, необходимо помнить, что брак может и распасться, но это не должно отражаться на общем семейном бизнесе.

Недостаточность делового воспитания, бизнес-обучения приводит к тому, что семейные взаимоотношения нередко ставятся во главу угла и при ведении бизнеса, что не только не позволяет его развить в полной мере, но и зачастую является причиной того, что бизнес закрывается вместе с уходом из него его создателя. Дети, не прошедшие должной школы, оказываются не способными продолжить начинания своих родителей. На сегодняшний момент это самый острый вопрос семейного бизнеса.

Следовательно, при развитии семейного бизнеса необходимо четко разграничивать сферу семейного и делового общения, закрепить обязанности членов семьи документально, выстроить систему подчинения и придерживаться ee.

Таким образом, можно прийти к заключению, что семья - особо функционирующий механизм. Его уникальность помогает развитию самого крепкого и эффективного бизнеса. Семейные партнёры, как правило, основывают исторический бизнес, способный выжить не одно десятилетие, а иногда перерастающий в целую эпоху. В то же время это один из самых сложных вариантов менеджмента, в котором психологический аспект влияет на основные факторы ведения дела. Уравновешивание, вечный поиск баланса, нахождение компромисса, неотступление от важных принципов - тонкие грани психологии семейного бизнеса.

\title{
Литературы
}

1. Волков Д. А. Семейный бизнес в России: социально-экономические аспекты управления: моногр. - М.: Креативная экономика, 2012. - 178 с.

2. Колин Л., Колин Л. Семейный бизнес: от конфликтов к успеху : практ. руководство по управлению семейным предприятием / пер. с англ. Н. В. Селиванова. - М.: Добрая кн., 2010.

3. Шнуровозова Т.В.. Семейный бизнес по-русски. - М.: Дашков и Ко, 2010. $-208 \mathrm{c}$.

\section{СТРАТЕГИИ СОВЛАДАНИЯ В РАБОТЕ НАЧИНАЮЩЕГО ПСИХОЛОГА (К ПОСТАНОВКЕ ПРОБЛЕМЫ)}

Шевцова И.А.

В наше современное время, в век быст, рых технологий, и с одной стороны, казалось прогресса в развитии, с возрастающими потребностями общества в реализации и поиска себя, как личности, будет всегда актуальны 
личные способности человека сохранять устойчивость к жизненным трудностям и проблемам и при это успешно развиваться. Вопросы поиска себя, стратегий совладания в различных ситуация, включая стрессовые, построение своей жизни, возможностей управлять своей судьбой будет присутствовать на всем жизненном пути человека.

Важно учитывать, что изучение феномена совладения обусловлено необходимость проводить эффективную коррекцию посттравматических состояний, после трагических событий, стихийных бедствий, а также при необычных или неблагоприятных условиях жизни.

Для психолога, начинающего свою профессиональную деятельность часто возникает стрессовая или кризисная ситуация в применении полученных, знаний, умений, навыков, а также в позиционировании себя в новой социальной роли. И в связи с этим возникают вопросы, каким-образом выработать эффективную стратегию совладания. Совладающее поведение позволяет начинающему психологу справиться со стрессом адекватными способами, которые соответствуют личности и ситуации.

В данной статье представлен краткий теоретический анализ исследования совладания в зарубежной и отечественной психологии.

Возникающий стресс, как следствие возникающего напряжения, влияет на весь организм в целом и если своевременно не оказать поддержку, влияние, то действия и последствия стресса могут быть достаточно разрушимыми для организма.

В зарубежной психологии используют термины: «сорing» («справляться» с чем-либо, к примеру, с проблемной ситуацией) и «defense» («защита», к примеру, от неприятных переживаний, мыслей или от фактов, грозящих нарушить позитивную самооценку человека).

Понятие психологической защиты (defensive behavior) появилось в психоаналитической школе (Freud, S., 1923, 1946, 1949; Freud, A., 1937, 1944). Согласно концепции психологической защиты Зигмунда Фрейда понятие «defense» обозначает защитную функцию эго или Я-структуры от осознания или принятия человеком неприятного факта жизни. Иными словами, под психологической защитой понимается тот или иной способ уклонения, или так называемого ухода, от осознания психологической проблемы и от необходимости ее разрешения. Согласно исследователям психоаналитической школы защитная реакция проявляется в различных формах борьбы Я с невыносимыми мыслями и болезненными аффектами, сопровождающими переживаемый человеком неосознаваемый им внутренний конфликт.

Термин «coping» был введен в тридцатых годах двадцатого столетия Гансом Гартманном (H.Hartmann, 1938/1957) в связи с необходимостью описания механизмов функционирования так называемой «свободной от конфликтов зоны Я» (conflict-free zone of ego). Изучение «coping» было продолжено следующим поколением исследователей психодинамической теории (T. Kroeber, 1963; N. Haan, 1963, 1969, 1974, 1977; R. White, 1974; V. Vaillant, 1977). В сороковых - шестидесятых годах двадцатого столетия концепция совладания начала активно использоваться в рамках изучения 
механизмов стресса (R. Lazarus, 1966, 1970; S. Folkman \& R. Lazarus, 1980, 1985), а также в связи с разработкой эффективных способов терапии стрессовых состояний, вызванных тяжелыми заболеваниями (F. Cohen \& R. Lazarus, 1973; В. Д. Тополянский, М. В. Струковская, 1986). [1;5]

Феномен совладания изучается как в зарубежной, так и в отечественной психологии. На данном этапе в зарубежной психологии разрабатывается три основных подхода.

Первый подход представлен эго-ориентированной теорией совладания (K. Menninger, 1963; V. Vaillant, 1977; T. Kroeber, 1963; N. Haan, 1963, 1969, 1974, 1977), берущей свое начало в психоаналитической теории Зигмунда Фрейда (1923) и работах Анны Фрейд (1937). С точки зрения психоаналитической теории, процесс совладания рассматривается в качестве специфического эгомеханизма, к которому человек прибегает с целью избавления от внутреннего напряжения (tension).

Согласно второй концепции совладание является относительно устойчивыми личностными предпосылками (traits), предопределяющими реакцию человека на тот или иной стрессовый фактор (R. Moose, 1974). Моуз различает активные и пассивные способы реагирования на стресс: первые считаются проявлением конструктивного поведения, вторые неконструктивного.

К третьему направлению относится когнитивно-феноменологическая теория совладания со стрессом, разработанная Ричардом Лазарусом и Сюзан Фолкман (R. Lazarus \& S. Folkman, 1984).[1;10]

Более актуальной является теория третьего направления. В теории совладания важным является как когнитивная оценка самим человеком, так и совладение с динамическим процессом, который зависит от специфики ситуации. Р.Лазарус и С.Фолкман выделили два типа совладания со стрессом.

К первому типу относится проблемно-ориентированное совладание (problem-oriented coping), связанное с разрешением стрессовой ситуации. Ко второму типу относится эмоционально-ориентированное совладание (emotionoriented coping), которое «преобладает в том случае, когда когнитивная оценка говорит о том, что ничего невозможно поделать» (Lazarus \& Folkman, 1993, с. 9). В зависимости от субъективной оценки возможности-невозможности чтолибо предпринять для изменения ситуации происходит выбор типа совладания: «Если когнитивная оценка говорит о том, что что-то можно предпринять, преобладает проблемно-ориентированное совладание» (Lazarus \& Folkman, 1993 , с. 9).[1;21]

Таким образом, согласно их подходу саму ситуацию изменить невозможно, но при этом эмоционально-ориентированное совладание позволяет изменить «интерпретацию произошедшего».

Изучение совладания в отечественных исследованиях в основном ведется в рамках анализа психических процессов, свойств и функциональных состояний людей, вовлеченных в сверхответственные, вредные и опасные виды деятельности. Так, работы К. К. Платонова (1960) посвящены изучению функциональных состояний и работоспособности человека. Особое внимание 
уделяется (В. А. Бодров, 1973, 1992; Л. Г. Дикая, 1985; П. Б. Зильберман, 1974) специальности операторов, профессиональная деятельность которых связана с высоким уровнем стресса. Исследование стресса и способов его снятия также проводится в связи с изучением экстремальных условий деятельности (Т.А.Немчин, 1977, 1983; В. И. Медведев, 1970, 1979; Л. А. Китаев-Смык, 1977, 1978), в частности условий деятельности пилотов, летчиков и космонавтов (К.К. Платонов 1960; В.Л. Марищук, 1963; В.Л. Марищук, К.К.Платонов, Е.А.Плетницкий, 1969; В.А.Бодров, Н.Ф.Лукьянов, 1981; В.А. Бодров, В.Б.Малкин, Б. Л. Покровский, Д. И. Шпаченко, 1984).

Изучается также исследование стрессовых нагрузок и способов их минимизации в спортивной деятельности (В.Л. Марищук, 1983; В.Э. Мильман, 1983; Ю. Ханин, 1987, Hanin, 2001).

Отечественные психологи Л. А. Китаев-Смык (1983), Е. В. Симонов (1970, 1981) рассматривают стресс в качестве особого психического состояния, связанного с возникновением эмоций, но не сводимого к ним. Исследователи считают, что стрессовое состояние детерминируется мотивационными, когнитивными и волевыми характеристиками личности. В. А. Бодровым (1995) сделана попытка дифференциации таких понятий, как «психологический стресс», «эмоциональный стресс», «психическое напряжение». В целях изучения психологического функционирования человека в сложных условиях вместо термина «стрессовое состояние» отечественными психологами был предложен термин «нервно-психическая напряженность» (Н. И. Наенко, 1976; Т. А. Немчин, 1983; В. Л. Марищук, 1983).[1;37-40]

Для личности любой стресс, кризис имеет свои положительные и отрицательные стороны. Вопрос самоопределения, поиска себя, своей профессиональной идентичности актуален и важен на всем жизненном пути человека. Молодые специалисты, окончившие вуз, испытывают потребность в применении и реализации полученных знаний, умений, навыков. Перспективным является изучение стратегий совладания начинающего психолога, так как показывает практика, с проблемой реализации совладания со стрессом встречаются и начинающие психологи.

\section{Литература}

1. Либина А. Совладающий интеллект: человек в сложной жизненной ситуации - М: Эксмо, 2008. - 408 с.

2. Перлмуттер Д. Зарядите свой мозг. - М: Эксмо, 2012. - 320 с.

3. Шипилова Е.В. «Формирование психологической готовности студентов-психологов к профессиональной деятельности», автореферат на соискание ученой степени кандидата психологических наук, М., 2007. 